\title{
Accuracy of the continuous glucose monitoring system in inpatient and outpatient conditions
}

\author{
C Djakouré-Platonoff, R Radermercker, G Reach, G Slama, JL Selam
}

\section{S U M M ARY}

Objective: To evaluate in inpatient and outpatient conditions, using only non-calibration data, the accuracy of the Continuous Glucose Monitoring System (CG-MS).

Research design and methods: Twelve, 21 and 20 type 1 diabetic patients participated in 3- day inhospital, 6-day ambulatory (i.e., 2 sensors worn consecutively) and 3-day ambulatory studies. Capillary glucose tests (7-8/day) served as comparisons. Pairs of data (excluding the 4 daily pairs used automatically by the CGMS for calibrations) were analyzed using correlation coefficient, error -grid analysis, and mean of absolute differences.

Results: Two third and half of the sensing days were qualified as "optimal", i.e., interpretable by the CGMS program in the inpatient and outpatient studies, respectively. Correlation coefficient was $0.92,0.81$ and 0.73 in the inpatient, 6 day outpatient and 3-day outpatient studies. $98 \%, 93 \%$ and $96 \%$ of the data fell in the A or B error-grid "clinically acceptable" zones. Mean absolute differences between sensor and glucometer values were $25 \pm 2,34 \pm 5$ and $32 \pm 5 \mathrm{mg} / \mathrm{dl}$.

Conclusion: CGMS may be used for assessment of glycemic trends, though accuracy is more in the range of glucometers than of laboratory tests. Inhospital utilisation improved accuracy and 6-day rather than 3-day sessions may be more appropriate to evaluate day to day reproducibility of glucose profile.

Key-words: Glucose Sensor · Hypoglycemia · Articificial Pancreas.

Djakouré-Platonoff C, Radermercker R, Reach G, Slama G, Selam JL. Accuracy of the continuous glucose monitoring system in inpatient and outpatient conditions.

Diabetes Metab 2003,29,159-62

\section{RÉ S U MÉ}

\section{Précision du capteur de glucose CGMS chez le patient hospitalisé et le patient ambulatoire}

Objectifs : Evaluer dans des conditions d'hospitalisation et ambulatoire, l'exactitude du capteur de glucose CGMS, en incluant seulement les données hors calibration.

Matériels et méthodes : Douze, 21 et 20 diabétiques ont participé respectivement à une étude intrahospitalière de 3 jours, une étude ambulatoire de 6 jours (avec 2 capteurs posés consécutivement) et une étude ambulatoire de 3 jours. Les glycémies capillaires ( 7 à 8 par jour) ont servi de données de comparaison. Les données appariées, excluant les 4 paires de données journalières utilisées pour la calibration automatique du CGMS, ont été analysées par les méthodes de corrélation, d'erreur grid, et par le calcul de la moyenne des différences absolues.

Résultat : Deux tiers et la moitié des jours d'enregistrement ont été qualifiés d'optimaux c'est-à-dire interprétables par le programme CGMS chez les patients hospitalisés et au cours des études ambulatoires respectivement. Les coefficients de corrélation étaient de 0,92, 0 , 81 et 0,73 dans les études intrahospitalières, ambulatoires sur 6 jours, et ambulatoires sur 3 jours. 98, 93 et $96 \%$ des données se sont situées dans les zones $A$ et $B$ de l'erreur grid c'est-à-dire les zones "cliniquement acceptables". La moyenne des différences absolues entre le capteur et les lecteurs de glycémie a été de $25 \pm 2,34 \pm 5$ et 32 $\pm 5 \mathrm{mg} / \mathrm{dl}$.

Conclusion : Le CGMS peut être utilisé pour apprécier les "tendances"glycémiques même si son exactitude est plus proche de celle des lecteurs glycémiques que de celle d'un appareil de laboratoire. L'utilisation intrahospitalière s'est avérée plus sûre et un enregistrement sur 6 jours plutôt que 3 jours dans les conditions ambulatoires, paraît plus approprié pour évaluer la reproductibilité journalière du profil glycémique.

Mots-clés : Capteur de glucose $\cdot$ Hypoglycémie $\cdot$ Pancréas artificiel.
Address correspondence and reprint requests to:

JL Selam. Service de Diabétologie, Hôtel Dieu, 1, place du Parvis Notre Dame, 75181 Paris cedex 4, France.

jl.selam@htd.ap-hop-paris.fr. jean-louis.selam@wanadoo.fr

Received: October 30, 2002; revised: January 20, 2003 


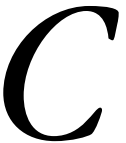

ontinuous glucose sensing has made significant progress in the last years, leading to commercial availability of some externally worn subcutaneous devices including the "Glucowatch Biographer" [1] and the Continuous Glucose Monitoring System (CGMS, Medtronic Minimed, Northridge, Calif, USA) [2].

Though the latter system is now widely used, there is still some questioning regarding the reliability of glucose monitoring [3]. Indeed, except in one article [4], a) it was not clear whether calibrations points were excluded from evaluation points to calculate accuracy, and b) the involvement of health care team, as well as the percentage of interpretable days of the continuous glucose monitoring sessions were not clearly identified in the majority of publications. Finally, most of those publications have involved directly or indirectly the manufacturer itself [5-7].

Therefore, we decided a) to evaluate the accuracy of the CGMS in inpatient conditions (i.e., CGMS was cared and the control blood glucose was supervised by nurses) and outpatient conditions (everything cared by patient), and b) to analyze data excluding calibrations points and using the usual indices (e.g correlation) but also the number of interpretable days.

\section{Materials and methods}

\section{CGMS}

The CGMS has been described in details elsewhere [2, 10]. Briefly it is a holter-style sensor system comprised of a) a pager-size glucose monitor b) a disposable subcutaneous needle-type enzymatic glucose electrode connected to the monitoring by a cable. The data may be retrospectively downloaded to a computer via a communication device and a special program (version 1.7, used for all the recordings). This program identifies the "interpretable days", i.e., those days when the automated comparisons between daily calibration values and sensor values provide a correlation coefficient $>0.79$ and mean absolute difference $<28 \%$ for a minimum number of pairs of values of 3 within $24 \mathrm{~h}$.

\section{In patient study}

Twelve type 1 diabetic patients ( $T a b$ I) gave written informed consent and the study was approved by the hospital ethical committee. The sensor was inserted by an experienced nurse in the subcutaneous tissue of the abdominal wall for a continuous monitoring of 3 days. Using a previously validated glucometer (Glucotrend ${ }^{\circledR}$ Roche), i.e., a capillary glucose value within $20 \%$ of a laboratory venous glycemia, and a technique validated and supervised by a nurse, the patients performed 8 capillary glucose tests over each $24 \mathrm{~h}$ (one every 3 hours). Four values were used for automatic calibration of the sensor, and 4 for evaluation of accuracy $v$ s capillary glucose values.

\section{Table I}

Clinical characteristics of subjects (mean \pm SD).

\begin{tabular}{lccc} 
& Inpatient & \multicolumn{2}{c}{ Outpatient Study } \\
& Study & 6 day & 3 day \\
\hline $\mathrm{n}$ & 12 & 21 & 20 \\
Sex (M/F) & $6 / 6$ & $12 / 9$ & $10 / 10$ \\
Age (yrs) & $42 \pm 15$ & $46 \pm 11$ & $45 \pm 12$ \\
Duration of & $19 \pm 11$ & $21 \pm 9$ & $21 \pm 12$ \\
diabetes (yrs) & & & \\
$\mathrm{Hba}_{1 \mathrm{c}}(\%)$ & $8.4 \pm 1.1$ & $7.7 \pm 0.8$ & $7.7 \pm 0.8$ \\
\hline
\end{tabular}

\section{Out patient study}

41 type 1 diabetic patients (Tab I) gave written informed consent and the study was approved by the hospital ethical committee. Twenty one patients used the sensor for up to 3 days, i.e., the nominal life of the sensor, and 20 for 6 days, i.e., they changed the sensor after 3 days. First insertion and education for second insertion was realized during a clinic visit in the hospital. The patients performed 7 capillary glucose tests per $24 \mathrm{~h}$ using a Glucotrend ${ }^{\circledR}$ glucometer, including 4 values for automatic calibration and 3 for evaluation of accuracy of the sensor.

\section{Statistical analyses}

Only "optimal" days, i.e., the days identified by the CGMS program as "interpretable" (see above) were used for calculations. Accuracy $v$ capillary glucose was measured using 3 different methods: a) Spearman correlation coefficient, b) Clarke error -grid analysis [8] and c) absolute differences [9]. Results are given as means \pm SD unless otherwise specified.

\section{Results}

\section{Inpatient study}

81 CGMS values (i.e., CGMS values at the time of capillary glucose tests, excluding calibration values) were judged by the CGMS program as interpretable over a number of 24 optimal days, i.e., one third of CGMS days were considered as "non optimal" by the program. The average number of calibration points was $4.2 /$ day. Correlation coefficient was 0.92 . Using the error-grid analysis, $82 \%$ and $16 \%$ of values fell in the A and B zones, respectively, i.e., 98\% of CGMS values were in the "clinically acceptable" accuracy range (Fig 1). Mean differences between CGMS and capillary glucose values were $25 \pm 2$ (SEM) mg/dl (Fig 2A).

\section{Outpatient study}

The number of "optimal days" was $3.1 \pm 1.9$ (SD) and $1.5 \pm 1.0$ in the 6 - day and 3-day sensing subgroups, respec- 

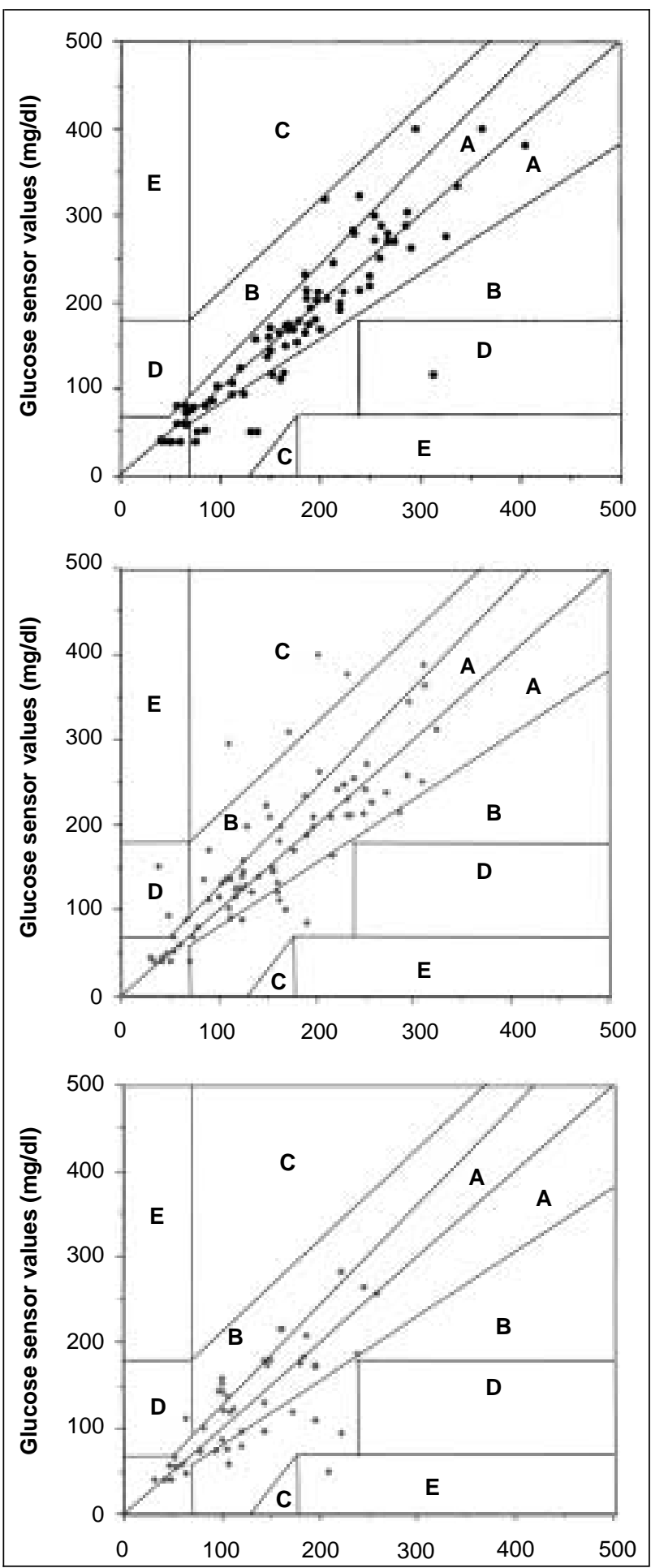

Figure 1

Error - grid analysis of inpatient group (A), outpatient 6-day subgroup (B) and 3-day subgroup (C) comparing CGMS glucose values to capillary glucose tests (values having served to daily calibration were excluded).

tively. Seventy nine pairs of data (excluding calibration values) were interpretable in the 6-day subgroup and 46 in the
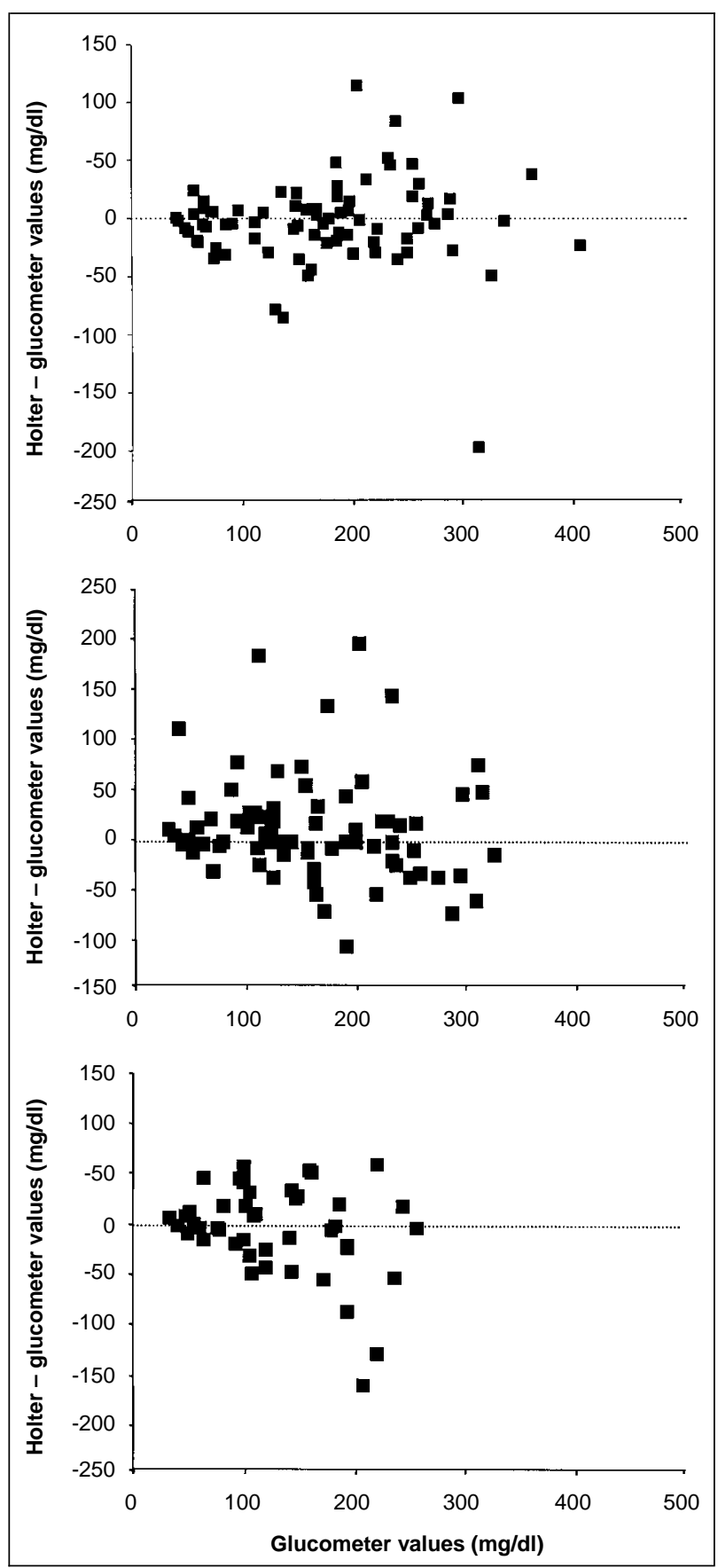

Figure 2

Mean of absolute differences between CGMS data (y) and capillary glucose values $(\mathrm{x})$. Other legends as in figure 1.

3-day subgroup. The average number of calibration points was 5.0 and 3.3/day, respectively.

Correlation coefficient was 0.81 and 0.73 , respectively. Error-grid analysis showed that $93 \%$ and $96 \%$ of CGMS (Fig $1 B$ and $C$ ) data fell in the $\mathrm{A}$ or $\mathrm{B}$ zones in the 6-day and 3-day subgroups, respectively. Mean absolute differences between CGMS and capillary glucose values were $34 \pm 5 \mathrm{mg} / \mathrm{dl}$ and $32 \pm 5 \mathrm{mg} / \mathrm{dl}$, respectively (Fig $2 B$ and $C$ ). 


\section{Discussion}

Our results confirm data from literature showing acceptable accuracy of the CGMS in patient and outpatient conditions [4-7]. However correlation with blood glucose values measured by a glucometer were slightly inferior to those reported in the literature: 0.9 when sensor was used and controlled in hospital under nurses supervisions, 0.8 when used during 6 consecutive days at home, and 0.7 when used during 3 days only at home. Differences between our data and literature may be due to our evaluation strategy excluding pairs of data having served to calibration (usually 3 to 4 per day). Confirming this assumption, correlation coefficient rose to 0.91 and 0.88 in the 6-day and 3-day outpatient studies when including calibration points into the calculation (data not shown), and are close to most recent reports [11].

As claimed by manufacturer, CGMS data should not be viewed as absolute values but as "trends" of glucose variations, i.e., shapes of the CGMS glucose profiles are more important to consider than isolated values. Our data confirm this view as we found global accuracy closer to the range of glucometers than to those of laboratory measurements. We cannot exclude that those differences may be due to the different milieus (blood $v$ interstitial fluid) where glucose was measured [12].

Indeed, though error-grid analyses showed that more than $90 \%$ of CGMS values were in the so called "clinically acceptable range", mean of absolute differences $v s$ capillary glucose levels were aproximately $25 \mathrm{mg} / \mathrm{dl}$.

Finally, we found that interpretable days during the sensing sessions varied between 1.5 to 2 out of the nominal 3 days of a sensor lifetime, suggesting that 2 sensors should be used consecutively (i.e., a total of 6 days, including 3 to 4 interpretable days), if one wants to appreciate the day-to-day reproducibility of glucose profiles. We can only speculate that the higher number of non interpretable days in our outpatients groups may be due to more frequent technical problems e.g disconnections.

In conclusion, our study confirms that CGMS may be used reliably for global retrospective assessment of glycemic fluctuations of patients though accuracy of evaluations of nocturnal hypoglycemias is controversed [13].

Inhospital use may be required if better accuracy of data is needed, and longer sessions may be required to better ana- lyze glycemic reproducibility. Cost-effectiveness of the system, though only potentially positive [14] should take into account the 50-66\% only, global good functioning of the system.

Aknowledgements - M.Taverna for his help in submitting the manuscript.

\section{References}

1. Garg K, Potts O, Ackreman R, Fermi J, Tamada A, Chase H. Correlation of fingerstick blood glucose measurements with gluco watch biographer glucose results in young subjects with type 1 diabetes. Diabetes Care, 1999, 22, 1708-14.

2. Mastrototaro JJ. The Minimed continuous glucose monitoring system. Diabetes technol Ther, 2000,2, 13-8.

3. Reach G. Letters to the editor. Diabetes Technol Ther, 2001, 3, 129-31.

4. Gross TM, Mastrototaro JJ. Efficacy and reliability of continuous glucose monitoring system. Diabetes Technol Ther, 2000, 2, 19-26.

5. Gross TM, Ter Veer A. Continuous glucose Monitoring in previously unstudied population subgroups. Diabetes Technol Ther, 2000, 2, 27 34.

6. Gross TM, Bode BW, Einhorn D, et al. Performance evaluation of the Minimed continuous glucose monitoring system during patient home use. Diabetes Technol Ther, 2000, 2, 49-56.

7. Bode BW, Gross TM, Thornton KR, Mastrototaro JJ. Continuous glucose monitoring used to adjust diabetes therapy improves glycosylated hemoglobin: a pilot study. Diabetes Res Clin Pract, 1999, 46, 183-90.

8. Clarke WL, Cox D, Gonder Frederic LA, Carter W, Pohl SL. Evaluating clinical accuracy of systems for self monitoring of blood glucose. Diabetes Care, 1987, 5, 622-7.

9. Martin Bland J, Altman DG. Correlation, regression, and repeated data. BMJ, 1994, 308, 896.

10. Hirsch IB. Hypoglycemia and the Hypoglycemic Unawareness Syndrome. Diabetes Technol Ther, 2000, 2, 581-7.

11. Metzger M, Leibovitz G, Wainstein J, Celaser B, Raz I. Reproducibility of glucose measurements using the glucose sensor. Diabetes Care, 2002, 25, 1185-91.

12. Choleau C, Dokladal, Klein JC, Ward Wk, Wilson GS, Reach G. Prevention of hypoglycemia using risk assessment with a continuous glucose monitoring system. Diabetes, 2002, 51, 3263-73.

13. Gowan KMc, Thomas W, Moran A. Spurious reporting of nocturnal hypoglycemia by CGMS in patients with tightly controlled type 1 diabetes. Diabetes Care, 2002, 25, 1459-503.

14. Skyler JS. The economic burden of diabetes and the benefits of improved glycemic control: the potential role of a continuous glucose monitoring system. Diabetes Technol Ther, 2000, 2, 57-512. 